\title{
Trainings in the context of future psychologists' rhetorical competence formation
}

\author{
T. Ya. Konivitska \\ Lviv State University of Life Safety \\ Corresponding author. E-mail: tvitska@gmail.com
}

Paper received 31.10.19; Accepted for publication 15.11.19.

\begin{abstract}
https://doi.org/10.31174/SEND-PP2019-209VII86-06
\end{abstract}
\begin{abstract}
The article describes the features and benefits of trainings and investigates the effectiveness of using the elements of trainings in rhetoric classes at higher schools. It is stated that training is one of the effective interactive methods of learning rhetoric, which promotes the development of speaking and thinking activities, interpersonal communication skills, as well as rhetorical skills. The use of elements of trainings in rhetoric classes ensures the effective formation of rhetorical competence according to professional orientation.
\end{abstract}

Keywords: rhetorical competence, rhetorical classes, trainings, active and interactive teaching methods, speaking and thinking activity.

Introduction. Examining the tendencies of the development of rhetoric as a science, we can state that nowadays the interest in studying oratorical skills has increased significantly in the system of both formal and non-formal education of Ukraine. The popularity of non-formal oratorical schools is determined by the latest approach to learning, focused on the development of practical skills through the use of innovative forms, methods and technologies of teaching. Rhetorical training at higher schools should be comprehensive, involving the introduction of modern methods of teaching rhetoric (effective methods, tools, and technologies) into the educational process in accordance with the international standards, features of professional orientation and requirements of the society to highly qualified professionals. Undoubtedly, rhetorical training should be professionally oriented, i.e., aimed at developing rhetorical skills necessary for future professional activities. One of the main types of teaching that meets these requirements is trainings, the elements of which are widely used at professional higher schools.

Literature Review. Theoretical and methodological principles of trainings were researched and introduced into the educational process by scientists and practitioners in the field of pedagogy and psychology, including N. Bogomolova, I. Vachkov, L. Miliutina, L. Petrovskaya, V. Fedorchuk, T. Yatsenko, etc. Elements of trainings in the context of rhetorical competence formation are developed and implemented into the rhetorical training by a number of researchers, in particular N. Holub, I. Harkusha, O. Zaliubivska, Z. Kunch, T. Symonenko, Y. Tarasevich, et. al.

The purpose of the article is to analyze trainings, to find out their role in the educational process and the importance for future psychologists' rhetorical competence formation.

Methods. Study and generalization of theoretical and practical teaching experience, observation, questioning, testing, study of educational products, etc.

Results and Discussion. Educational practice shows that effective formation of rhetorical competence at higher schools depends on the use of appropriate methods of rhetorical training, the optimal selection of modern forms, methods, tools and technologies of teaching and learning aimed at the development of rhetorical knowledge, skills and abilities. Following other researchers, we believe that in the methodology of rhetorical training at higher schools it is advisable to combine various types of education, namely: collective, cooperative, training and professionally situational ones.

Nowadays, interactive teaching methods are being increasingly introduced into the educational process. It should be noted that the views of researchers on the problem of the development and application of elements of interactive learning in pedagogical science and practice are ambiguous. There is no consensus on what to consider as activity and interactivity, as well as to consider interactive construction of pedagogical interaction as teaching methods or technologies. Interactive learning is focused not only on interaction of students with a teacher, but also with each other, that is, it gives preference to the students' activity and independence in the learning process. The role of the teacher is to direct the students' cognitive activity to achieve the goals of the lesson and positive results, because awareness and better memorization occur through self-study [1, p. 133]. We agree with the opinion of researchers that passive observation does not give positive effects for the rhetorical competence formation, since the relevant skills are acquired only as a result of long-term practice. It is necessary to improve communication skills in different situations constantly, to plan, implement, analyze, and adjust them meaningfully that can be achieved through trainings. Therefore, it is advisable to use trainings as a basis for the methodology of rhetorical competence formation [6].Trainings are now quite common in non-formal education for the personal development of professionals and their professional realization. Elements of rhetoric trainings are also increasingly used at many higher schools.

After analyzing the scientific, pedagogical and methodological literature, we can note that there is no single interpretation of trainings: some consider training as a method, others consider it as a technology or even a form of teaching. There is also disagreement regarding its attribution to active or interactive learning (active or interactive methods). For a better understanding, we will present various definitions of the concept of training and describe the main features of trainings for the development of rhetorical competence. Training (from an English word "to train" - educate, instruct, teach) is 1) a planned process of modifying (changing) attitudes, knowledge or 
skills through the acquisition of certain experience to achieve effective activities; 2) a set of exercises for training in anything; 3) a form of group work during which active participation and creative interaction of participants with each other and with the leader of the lesson (a coach) is realized [1, p. 134]; 4) a part of the process of learning or professional adaptation, which enables students to apply the acquired knowledge in practice, transforming them into skills [7, p. 102]. Researchers note that the training of rhetorical competence development is the basis of personality formation, which may be subject to other types of trainings, such as leadership or creativity ones, etc. [8, p. 12]. The training of rhetorical competence development is considered one of the varieties of psychological trainings aimed at helping a person realize his / her own shortcomings in the development of rhetorical skills, identify and assess potential opportunities, as well as implement the acquired knowledge into practice [2, p. 104]. Various psychological trainings are now widespread and in great demand in society and education, especially in corporate practice. The training also allows you to destroy the stereotypical ways of behavior and thinking, solve the participants' personal problems and, therefore, we emphasize the need for trainings at higher schools, since certain professionally important skills can only be formed and "polished" through trainings, and their use while teaching rhetoric promotes more active acquisition of knowledge, effective development of rhetorical skills and professional qualities, etc. [3, p. 34].

Based on the definitions analyzed, we believe that trainings are one of the important teaching methods in the system of future specialists' rhetorical training. We consider the training of rhetoric competence development to be the most effective interactive method of practical rhetoric education at higher schools, which promotes communicative-cognitive activities, development of rhetorical knowledge and skills, including interpersonal communication, and provides effective formation of future psychologists' rhetorical competence.

Researchers present specific characteristics and features that distinguish trainings from other types of vocational education. The most important, in our opinion, are the following: a specific goal (question-oriented and answer-seeking, gaining experience, assisting participants in self-development, etc.); appropriate combination of different training methods and techniques (presentation of information according to individual characteristics of participants' perception); team and group organization of training (adherence to the principles of group work, enabling each participant to identify himself / herself with others and gain new experience); active work of all the participants (free expression of their opinions, interaction between the coach and the group, as well as between the participants); "here and now" principle (emphasis on relations between the group members which are being developed and analyzed while solving problematic real situations); informal cooperation (defined spatial orientation, atmosphere of openness and freedom of communication between participants, psychological security that promotes communicative, emotional and intellectual feedback, reflection) [2, p. 104; 4, p. 137-138].

According to the introduction and use of active and interactive teaching methods, it is necessary to understand and re-think the role of a teacher in modern higher education. The main tasks of a teacher while working with a group in a rhetoric classes with elements of trainings or during the training of rhetoric competence development are the following: to facilitate the participants' understanding of the purpose and objectives of the trainings, to motivate students to work during and after the training, to create a trusting atmosphere for each participant to see everyone, communicate freely with everyone and with the teacher (leader, coach) [8, p. 78]. In accordance with the rapid development of the society, continuous informatization promotes openness and accessibility of information, use and implementation of modern methods and innovative teaching technologies. Therefore, we believe that a creative teacher embodies and combines various roles depending on the learning situation and the students' needs, e.g.: a teacher as a facilitator - develops the potential of the group, supports and organizes effective individual and group work; a teacher as an advisor and mentor - motivates, facilitates weaknesses and provides recommendations and tips for improving skills, establishing feedback; a teacher as an expert - the teacher's experience and knowledge enables him / her to be an expert, who guides, directs, evaluates the reliability of information; a teacher as a judge - honestly assesses, creating an atmosphere of trust, does not criticize during rhetorical training, but points out to the elements that can make public speaking and communication more interesting and better, as well as informs about the progress in learning; a teacher as a model to follow - possesses all the components of rhetorical competence (a good speaker, which is an example for students) [5, p. 7-9]. These qualities, certainly, are extremely important for a teacher to conduct the trainings of rhetorical competence development.

As our scholars and practitioners point out, and our own experience in teaching rhetoric shows, conducting trainings at higher schools has a number of significant difficulties, but it is quite real. The difficulty is that the effective conduct of different types of rhetorical competence trainings requires a small number of students (10-12 people), hence, at higher schools one cannot enroll in even one academic group. Such forms of work should be anticipated and organized accordingly. However, we believe that it is advisable to use the elements of training in each practice session compulsory and regularly in the course of rhetorical training. It should be noted that at higher schools it is necessary to use training sessions, which are a significant modification of the psychological concept of "training" and its traditional elements and procedures [8, p. 10-11].

Trainings of rhetorical skills development require a combination of different ways of pedagogical interaction, but the training session should be aimed at updating the acquired knowledge in practice, and the formation of professionally oriented rhetorical skills. Thereby, during their conduct, it is advisable to give a minimum of theory, whereas to pay more attention to the practical aspects that will be used in further professional activities.

The basis of rhetorical skills development is the collective communicative-cognitive activities in the classroom, which involves the use of games, exercises that contribute to the improvement of communicative-cognitive abilities; role-playing and business games that allow you to simu- 
late real life and professional situations; expert work that enhances the ability to track the advantages and disadvantages of other people's speech activity; reflection on the effects of one's speech activity (it is especially effective when recording one's own speech on video or audio); writing and solving communicative, logical, psychological and ethical tasks; creative activity of students (creation of linguistic expressions about a specific situation and genre) [2, p. 104].

According to the laws and objectives of rhetoric, the following groups of trainings are distinguished: development of proper pronunciation, culture of speech, development of voice, intonation, diction, breathing techniques, improvement of non-verbal communication (facial expressions and gestures), acquisition of art of public speaking, reciting, improvising, different types of disputes (debates), etc.

Nowadays in higher education the most popular are communication trainings (training of communicative, rhetorical competence), because in the context of communication a person is realized at different levels: mutual influence, activity, information exchange, perception, interpersonal relations, as well as exchange of norms, values, social behavior which can occur simultaneously [8, p. 101]. Such trainings are aimed at developing communication skills and proper behavior; acquiring skills to establish contact with the interlocutor, perceive and understand emotional state, non-verbal information, properly conduct the conversation or business negotiations; understanding and removing barriers to communication; mastering constructive ways of coping with conflict situations; developing abilities to adequately perceive and evaluate rhetorical skills (to reflect); and forming socially perceptual sensitivity, empathy, tact, etc. [4, p. 138].

Taking into consideration the peculiarities of rhetorical education, we propose the following indicative plan of the training of communication skills development for future psychologists: speech-rhetorical warm-up, creative tasks to increase vocabulary, the development of monologue speech, dialogic forms of work, tasks of understanding and improving the non-communication, (simulation of professional situations), analysis and reflection (oral or written).

It should be noted that psychological trainings are an important aspect of psychologists' work in the modern world, so psychology students should be competent in the training work. Their future professional activities involve organizing and conducting full-time or distance training work, which requires mastery of public speaking and presentation skills. To conduct effective psychological trainings and presentations in their future work, psychology students should practice in public speaking in classes, using the laws of rhetoric and all possible means of capturing the attention of the audience: content (information, various forms of presentation of the material, etc.), psychological (personal rapprochement, calls to authority, etc.), verbal (rhetorical questions, stylistic figures and tropes, etc.) nonverbal (gestures, facial expressions, intonation, visual contact, etc.). An important aspect in the development of training activities is the defense of the individual work for psychology students, which is provided in the form of a training for their classmates on a topic chosen independently in accordance with their professional orientation. A prerequisite is compliance with training requirements.

Conclusion. Trainings are one of the most effective interactive methods of practical rhetoric education since they promote the development of communicativecognitive activity, interpersonal communication skills and rhetorical skills. The use of elements of trainings in rhetoric classes provides for effective rhetorical competence formation according to the professional orientation in higher education, and for psychology students they also have a significant professional context.

\section{REFERENCES}

1. Borovyk L. Formation of psychological and pedagogical competence of future border officers: theory and practice: monograph. Khmelnytskyi: NADPSU Publ., 2018. 292 p.

2. Harkusha I. V Training as an interactive means of forming rhetorical skills of advertisers in the process of professional education. State and Regions. Series: Social Communications. 2015. No. 1 (21). P. 103-107.

3. Holub N. Effective methods and tools for teaching the rhetoric to future teachers. Bulletin of Izmail State Humanities University. 2008. No. 25. P. 31-35

4. Keryk O. Use of training technologies in the professional education of social professionals. Youth and the Market. No. 2 (121). 2015. P. 136-140.

5. Guide for Adult Learning Specialists / Ed. T. Urdze; DVV. International in Ukraine. Kiev: Context Ukraine Ltd, 2016. $84 \mathrm{p}$.

6. Simakova E. S. Rhetorical competence in teacher training. Bulletin of S.A. Yesenin State University of Ryazan. 2007. No. 17. P. 40-50.

7. Tkachuk T. L. Training as a means of optimizing interaction between students. Scientific Bulletin of Kherson State University. 2015. Vol. 4. P. 101-104.

8. Fedorchuk V. M. Training for personal growth: textbook. Kyiv: Center for Educational Literature, 2014. 250 p. 